\title{
THE PRESENT STATE OF OUR KNOWLEDGE OF HAY-FEVER.
}

\author{
(BEING A PAPER PRESENTED AT THE BERLIN CONGRESS \\ OF THE ROYAL INSTITUTE OF PUBLIC HEALTh.)
}

By Prof. W. P. DUNBAR, M.D.

(Director of the State Hygienic Institute, Hamburg.)

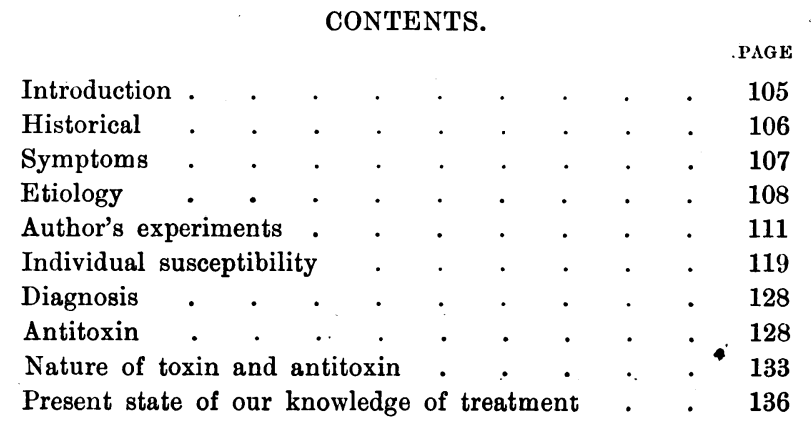

\section{Introduction.}

IN 1902 the investigations on hay-fever undertaken by me many years previously were brought to a temporary conclusion and their results published ${ }^{1}$. I advanced the theory that hay-fever is a disease caused by vegetable poisons contained in the pollen of certain plants. These substances were connected with the proteid of the pollen grain and of a highly specific character. It was thus possible to decide by means of the isolated poisonous pollen proteid, whether a given disease is identical with hay-fever or not. In $1903^{2} \mathrm{I}$ asserted more forcibly that

1 Dunbar, Zur Ursache u. spezif. Heilung d. Heufiebers, 1903. Verlag Oldenbourg, Miinchen.

2 Dunbar, "Zur Frage betreffend die Ätiologie u. spezif. Therapie des Heufiebers." Berliner klin. Wochenschr. 1903, Nos. 24-26.

Journ. of Hyg. xIII 
it was possible to obtain a specific antidote by inoculating pollen proteid into animals, e.g., rabbits or horses. With such an antidote it would be possible (1) to neutralise the pollen poison in vitro so that it would no more produce morbid symptoms in hay-fever patients. Further it would be possible (2) by this specific antidote to cure symptoms of the disease already developed. By the timely application of the antidote it would (3) be possible to prevent the onset of hay-fever symptoms.

I was subsequently ${ }^{1}$ able to show that by suitable application of the antitoxin hay-fever patients could be relieved from their predisposition, could be immunised to such an extent that they could do without the use of the antitoxin or any other remedies and yet remain free from hay-fever.

Whereas Th. Albrecht, Secretary of the German Hay-fever Association, regards my first publication as a turning point in the history of hay-fever, other colleagues have been less kind in their judgement, and some declare that $I$ have not discovered anything new. Likewise the verdict of laymen, especially of patients, alternates between the two extremes. Some are most grateful, whilst others consider my specific treatment useless. In view of these discrepancies of opinion I shall allow myself to revert to the developments in our knowledge during the last ten years to see which of my original assertions have proved correct and which incorrect.

\section{Historical.}

Whether we are justified in regarding hay-fever as a product of our modern civilisation I am inclined to doubt even more now than 10 years ago. In this period much has been published both in the medical journals and in the newspapers-the latter of course, so far as it dealt with my work, without my initiation and against my wish. Yet in spite of these numerous publications there are still many hay-fever patients who are completely unaware of the nature of their disease. Even in Hamburg on the occasion of a scientific exhibition where my hay-fever investigations were demonstrated, several grown-up residents asked me to determine whether they were hay-fever patients. What astonished me even more was to learn again and again that there are still physicians who deny, or are ignorant of, the existence of hay-fever. In view of this slowness of apprehension, a very general characteristic

1 Dunbar, “Zur Ursache u. spezif. Heilung d. Heufiebers," II. Deutsche med. Wochenschr. 1911, No. 13. 
of the human race, it would appear risky to assert that there could have been no hay-fever patients 500 years ago simply because no case histories have been preserved from those times. It is quite possible that the disease was fairly prevalent even then but that the scientist was wanting to observe the seasonal incidence of the disease, and to bring this to the notice of the public. The oldest convincing case history on record was given by Benningerus in the year $1673^{1}$. He described the case of a lady who suffered from coryza for several weeks in every year at the time of flowering of the roses. A who!e century elapsed before hay-fever was next mentioned by an English physician Heberden. But only in the year 1819 the accurate clinical description of the disease was given by a second English physician, John Bostock, himself a subject of this disease. The description given by Bostock was so complete and accurate that very little cause has since been found to alter or to add to it. It is true Bostock only knew the European type of hay-fever, not the autumn catarrh of America and the other types of the disease to which I shall refer presently.

\section{Symptoms of hay-fever.}

When the time of suffering approaches, the patients begin to experience from time to time itching of the inner canthus of the eye and the caruncula. This itching sets in, disappears and need not recur for several days. Then it is usually more severe, and one observes marked congestion of the caruncula and perhaps of the adjacent portions of the conjunctival membrane. This is followed by occasional, mild sueezing attacks. Suddenly the disease becomes much more severe. During a walk in warm sunny weather, the patient is attacked by convulsive sneezing fits which hardly give him time to breathe. The eyes itch intolerably, the conjunctiva becomes fiery red and oedematous. Nasal respiration becomes obstructed, the mucous membrane of the mouth and palate tickle unbearably, and this sensation proceeds through the Eustachian tube into the tympanic cavity. This attack is followed by a condition of weakness and enervation which may be so severe that the patient is unable to sit upright in his chair; at the same time the loss of all energy produces a profound mental effect. In many patients the symptoms are intensified by asthmatic attacks which prevent their

1 With regard to the following older publications, the reader is referred to Sticker's paper “Der Bostock'sche Sommerkatarrh (das sogenannte Heufieber)" in H. Nothnagel's Spezielle Pathologie und Therapie (Vienna, 1896) and to my first publication (see p. 105). 
finding any peace even at night. Lastly, many patients suffer from intolerable pruritus.

The most peculiar feature of the disease is that on certain days all symptoms disappear, the patient appears to be completely cured, and almost immediately afterwards is re-attacked most severely by all the symptoms described. This enigmatic condition of alternating disease and health lasts as a rule for six to eight weeks, after which period the symptoms gradually decline. The attacks are milder and less frequent, and resemble those occurring at the commencement of the disease; ultimately they quite disappear. But in the ensuing year they recur punctually, and whoever has once suffered from hay-fever as a rule remains its victim all his life.

The disease has always been called "hay-fever," because the patients remarked the regular incidence of the disease with the bay-making season and because they had the sensation of suffering from a feverish disease. Yet thermometric observation hardly ever shows an increase in the body temperature.

In the United States, the same type of hay-fever occurs, but it is less frequent than a similar type of the disease which occurs with the same symptoms in the autumn and also lasts about six weeks.

\section{The etiology of hay-fever.}

As is shown by this description, Bostock has taught us to recognise a well defined disease. Yet a long time elapsed before this knowledge was generally accepted by medical mei. Even nowadays hay-fever is hardly mentioned in the clinical instruction of our students, and many doctors must admit that they have only by chance heard of the existence of the disease. This is remarkable in view of the fact that hay-fever is one of the, if not the most common disease. It is true that it is not one of the scourges endangering human life. But hay-fever is a most troublesome condition, and many patients are so worn out by it every year that they lose all pleasure in life and only yearn for the end of their life of suffering. As soon as the period of disease is over, all is soon forgotten. The patient is donbly happy with the reawakening of a feeling of health and it is only when the next period approaches that he begins to feel anxious and worried. For this reason hay-fever is comparable to sea-sickness; which also has terrors only for him who has once suffered and is forced to undertake a fresh sea voyage. Such sufferers share the lot of the hay-fever patient, that clinical medicine 
gives them hardly any serious consideration, whilst they are an incomparable field of operation for pharmaceutical industry which every year brings forth fresh remedies for both diseases, stated to be infallible, yet none of which really helps.

One of the chief reasons why doctors have shown such scanty interest in hay-fever is perhaps to be found in the general view that the majority of the patients are nervous persons, easily influenced by suggestion, or, in other words, that the disease is not a real but only an imaginary one.

Bostock thought otherwise. He believed in an external irritating cause which he sought in moist heat, intense light, and dust. Yet all these stimuli are not characteristic for the period of hay-fever. Elliotson was the first to suspect the pollen, and in 1873 Blackley lent further weight to this supposition by very ingenious experiments. $\mathrm{He}$ collected the pollen on glass slides coated with glycerine, and was thus able to prove that the pollen is carried through the air for great distances and that particularly in the hay-fever season it is present in great quantity in the atmosphere. He was able to produce asthmalike attacks in hay-fever patients by inhalation of pollen. By rubbing pollen into the scarified skin of the fore-arm and leg he induced erythema. Blackley found many believers in his hypothesis in his day but in the course of time his opponents gained the supremacy.

With the commencement of the bacteriological era, scientists were inclined to regard hay-fever as an infectious disease. Influenced by Pasteur's publications, Helmholtz was one of the first (1867) to observe peculiar microbes resembling vibriones in the nasal secretion and to regard them as the cause of the disease. Heymann and Matzushita (1901) carried out experiments which led them seriously to doubt the pollen theory. They inclined to the view that hay-fever was an infection produced by bacteria. They thus confirmed the etiological hypothesis of Georg Sticker (1896) who was led by a critical consideration of all previous observations to regard hay-fever as an infectious disease. This excellent scientist then stated his belief that the conviction of the parasitic nature of hay-fever expressed by Binz would be decided in favour of, and to the glory of, Helmholtz, as soon as the investigations were undertaken in the right direction. Since then however Sticker ${ }^{1}$ has recognised my theory as correct.

A second, still older hypothesis has found numerous supporters up to the year 1902. According to this view, the disease is caused by the

1 Sticker, 1912, pp. 141, 144, 145, 159. 
odorous emanations of plants. Some authors go so far as to characterise these emanations as "fine smelling particles, finely divided evaporating essential oils, or some problematic substances which develope under the influence of intense sunlight at the time of the first flowering, especially of the rye."

Etiological research into the causes of hay-fever was particularly complicated, because several idiosyncrasies were uncritically confused with hay-fever in consequence of iusufficient attention being given to the seasonal incidence of this disease. Thus the zoologist Charlton Bastian regularly observed symptoms resembling this illness when he touched certain worms (Ascaris megalocephala) which he preserved in spirit in his collection. By chance this scientist's lecture on Ascaridae coincided with the hay-fever season, and it was inferred that Bastian was a hay-fever patient. It has since been found that these worms contain certain substances which produce hay-fever-like symptoms in some persons. Similarly the hyper-sensitiveness of certain persons towards cats, horses and other animals was confused with hay-fever and used as a proof that all such observations and symptoms were purely imaginative, and that they were comparable to the stories that persons had hay-fever symptoms when looking at artificial roses or the picture of a field of corn. Such deductions gradually led to the conviction that hay-fever was nothing but an hysterical manifestation.

It can be considered as established that certain people suffer from hay-fever-like symptoms when coming in contact with cats, mice, dogs or horses. My own investigations have shown me that such diseases are quite independent of hay-fever and represent a special disease. Thus, e.g., in the case of a lady who suffers from hay-fever-like symptoms whenever she touches cats, I found experimentally a very marked idiosyncrasy to cat's saliva. I shall recur to this question later on (see p. 127) and would now only state that such observations open up a new and probably extensive field of research. I should be very grateful if such patients were referred to me whose illness falls under this category. Their number probably is not very large.

Many of the stories which led to the view that hay-fever was a psychical ailment have been thoroughly disposed of by Geory Sticker (1896), so far as that was possible with the knowledge then available. From the publications appearing since that time one might suppose that the bacterial hypothesis of hay-fever had again become predominant. Yet all hay-fever patients who lived through those times 
received a very different impression. They suffered under the general assumption that only hysterically predisposed persons were subject to hay-fever. They therefore hardly dared to mention their ailment. They retired from their acquaintances as soon as the hay-fever period approached, for they feared to be looked upon as imaginary invalids and thus to lose the right of being considered as normal, sensible individuals. The majority of physicians at that time still looked upon hay-fever as a nervous disease due to suggestion. Several authors asserted it to be the result of a disorder of the sympathetic nervous system, whilst the hypothesis most generally believed attributed it to psychical trouble. Thus hay-fever patients suffered ridicule from their friends and even their physicians, and it was even seriously considered whether they ought not to be excluded from the world and confined in asylums! In $1902 \mathrm{~J}$. Rudolph published his view that hay-fever was a degenerative psychosis. He distinguished a hysteroid and an epileptoid form of spontaneous hay-fever. According to him there could be no doubt that it belonged to the realm of psychopathology, and treatment would thus have to proceed from the psychical side.

\section{My experiments on the etiology of hay-fever.}

No one who takes the trouble to study the literature on the causes of hay-fever up to 10 years ago will obtain the impression that up to that time any author had expressed a clear and correct view as to the nature of this disease.

As a very sensitive hay-fever patient I had for a number of years been in a position to investigate the different hypotheses as to the causation of hay-fever. Passing over the theory of local neurosis, of emanations and odours, and the bacterial theory, I gained the firm conviction that only the pollen theory could be correct. A detailed description of the observations which impressed this view upon me will be found in my hay-fever monograph quoted previously. The decisive experiment however could not be performed for several years owing to the difficulty of obtaining pure pollen. To-day this fact appears almost incredible in view of the exceedingly simple technique which I afterwards elaborated. Therefore I would at least mention that for several years I consulted different botanical experts as to the best way of collecting a large quantity of pollen. Various methods were suggested, e.g., to lay out large sheets on meadows. My own idea was to aspirate 
large volumes of air through bottles, etc. None of these methods was successful. At last I thought of the simple and most natural plan, viz. of shaking flowering ears of corn, e.g. wheat, and to collect the pollen falling from them. Still better results attended my subsequent plan of cutting the stalks just before the beginning of flowering and of placing them in water in a warm room. It was thus possible to collect any amourit of pollen rapidly, and what was most important to obtain the different kinds of pollen absolutely separate and free from all impurities, even microbes.

Having thus collected pollen of wheat, rye and ray-grass (Lolium perenne) the most important question was at once decided. The application of a barely visible trace of pollen to my conjunctival or nasal mucous membrane almost instantaneously produced most intense symptoms of hay-fever. The same experiment had a negative result in a laboratory attendant who was not a hay-fever patient. Within a few days these observations received further confirmation by experiments on two of my assistants who happened to be hay-fever patients and several others not thus predisposed. The results were entirely convincing. The hay-fever patients reacted in the same manner as myself, the remainder proved completely refractory to the administration of pollen. These experiments were afterwards performed with uniform results on a large number of hay-fever patients and normal individuals.

The next question of importance was whether this poison was active outside of the hay-fever season. Formerly the pollen theory had been attacked by the argument that the same pollen which were active during the hay-fever season were inactive afterwards. Thus, e.g., Sticker believed Woodward to have demonstrated pollen to be inactive outside of the hay-fever season. He therefore inferred that besides the personal susceptibility the hay-fever attack depended upon the critical season. The nature of this critical season was understood by other authors in the light of an internal change, a kind of spring evolution, taking place in the patients at this time of the year. This view did not appear to me to be justified, since this internal change would have to take place once a year in European patients in the spring, whereas in some of the American patients who suffer in spring and autumn the change would occur twice a year.

My experiments had the following result. Pollen which were carefully dried immediately after collection always proved active. But pollen placed in glass-stoppered vessels directly after collection underwent decomposition which was rendered obvious by liquefaction. Such 
pollen in which the poisonous proteid was decomposed by the action of the enzymes always present in the pollen grain have since repeatedly been found inactive. This observation by the way affords a simple explanation of the occasional occurrence of hay-fever attacks in winter. Pollen which settle in a dry locality may retain their activity through the winter, and even for many years. In a flower which had been preserved for 11 years in a collection an unimpaired action was demonstrated. On the other hand, in pollen settling in the open the poisonous ingredient is destroyed by the first rainfall.: Since pollen is carried down from the air by rain, a simple explanation is afforded for the hitherto inexplicable cessation of the hay-fever attacks on certain days. These days have been definitely proved to be the rainy days.

The grass pollen thus isolated had therefore served to fulfil the chief postulates of etiological proof which I had laid down at the beginning of my investigations. The supposed etiological agent, if free from any contamination, must cause hay-fever in the susceptible person at any season of the year, but must be absolutely inactive towards normal persons. This was not however the end of the question.

The grass pollen granules are so small as to be hardly recognisable with the naked eye, yet both in their physical structure and their chemical constitution they are very complex. Many pollen grains are armed with sharp prickles. Partizans of the pollen theory previously believed these prickles to be the cause of hay-fever. They supposed the hay-fever patients to be extremely sensitive individuals whose mucous membranes react intensely to a mechanical stimulus which has no effect upon the mucous membranes of normal persons. As it happens; some of the pollen grains which were formerly regarded as the principal causes of the disease have a rough or prickly surface. Besides, the earlier supporters of the pollen theory thought chiefly of the pollen of such plants whose flowers have a penetrating odour. The disorder was therefore frequently designated not as hay-fever, but as rose flower fever, lime flower fever, etc. These views were at once discarded when I demonstrated that the pollen of most of the plants which I found active have an absolutely smooth surface. This is true of all species of Graminaceae, 32 of which I investigated. The grass flower, too, has no scent.

The flowering period of the lime and rose usually coincides with that of the grasses. But in $1902 \mathrm{I}$ was able decisively to disprove the obstinate belief of many hay-fever patients in the importance of the 
lime flower. For in this particular year the flowering of the limes had been delayed in our neighbourhood for three to seven weeks, whilst the grasses flowered at the usual time. The chief period of illness in our patients was over when the lime flower attained its maximum, and thus for once they were able to enjoy with impunity this scent which in other years had filled them with dismay.

Likewise in 1912, when the first half year showed quite abnormal climatic conditions, the lime did not begin to flower until several weeks after the grass, i.e. at a time when the acme of hay-fever had passed. G. Sticker ${ }^{1}$ still lays stress upon the etiological importance of the lime flower for certain patients and supports this with the assertion that the number of my experiments is still insufficient.

On the contrary I must point out most emphatically that in not one case has it been demonstrated that hay-fever patients can be influenced by lime flowers, although since my first publication I have constantly experimented in this direction and have since administered lime pollen to a number of hay-fever patients with absolutely negative effect.

Still, I can understand the obstinacy with which patients believe in the causation of hay-fever by the scent of roses and limes. For many years I myself banished every rose and every other scented flower from my rooms during the hay-fever season and was convinced of having thus reduced my sufferings. This result was however due to my having simultaneously kept my windows scrupulously closed.

Almost simultaneously with the grasses, the pines (Pinus silvestris) begin to flower. They too are anemophilous and disperse so large an amount of yellow pollen that it occasionally fills the air with thick clonds. In such cases one speaks of "sulphur rain." Against the energetic opposition of several patients I was able to prove this pollen also to be innocuous.

A number of similar and varied experiments showed with certainty, in opposition to Blackley's assumption, that only certain, specific pollen cause hay-fever, whilst other pollen, even if armed with sharp spikes, are harmless.

We will now consider emanations, scents, essential oils, etc. If a vessel containing considerable quantities of grass pollen is opened, a honey-like odour is noticed. This is devoid of any influence upon hay-fever patients. The harmlessness of rose-scent and the still more frequently incriminated lime-scent has been repeatedly proved by

1 Sticker, Das Heufieber und verwandte Stïrungen, 1912, p. 21. 
me in an extensive series of experiments. There remained only to determine the effect of essential oils. The oily and waxy constituents of pollen when applied to the eye or nose of hay-fever patients in small quantities produced a burning sensation. This was however quite different from the peculiar nettlerash-like itching which every hay-fever patient knows and which can hardly be confused with any other sensation. What was even more important, these substances affected normal persons in the same manner. Under ordinary conditions the quantity of such alcohol- and ether-soluble substances coming in contact with our mucous membrane is so slight that the threshold of stimulation is not passed and no such sensations can develop.

The pollen of grasses are distinguishable from those of many other plants by the presence of a great number of small rods resembling bacteria. These had already been noticed in 1877 by Patton. He stated that the rods showed energetic movements when they emerged from the pollen grain and inferred that they were the active principle of the pollen, that they penetrated actively into the mucous membrane and the circulation, thus producing the symptoms of hay-fever. For a short time, I too was inclined to attribute an etiological importance to them. I thought that they did not consist of pure starch, but of a mixture of starch and proteid. As soon as I had obtained a sufficient quantity of grass pollen these bodies could be isolated by repeated centrifuging and washing: they were then shown to be inactive towards hay-fever patients.

Certain considerations to which I shall refer later soon led me to believe that the active principle was a proteid. In this view I was confirmed by the observation that the alcoholic precipitate obtained from the salt extract of a small amount of pollen was intensely active upon hay-fever patients but not upon normal persons. Later, when larger quantities of pollen had been collected, my etiological investigations were continued with the isolated proteid of grass pollen. Against this procedure the objection has been raised that I was not working with the genuine poison but with a denaturated poison. This assertion is entirely unfounded. My critics have neglected to furnish any proof of their assumption. It is obviously far more scientific to work with the isolated poison than with the entire pollen or with the unstable pollen extract. This extract I also employed in my earlier investigations, but only until I had determined that the poisonous principle was bound up with the proteid. Subsequently 
Dr Kammann' at my request sought to determine which portion of the pollen proteid is the active principle. He found this to be the albumin fraction, whilst the globulins proved quite harmless to hayfever patients.

Recently, Kammann has carried the purification of the poison still further. For this new toxin, which will be described in a later publication, the following points are of importance: (1) addition of diastase to remove the starch rods, (2) extraction with sterile distilled water (instead of salt solutions), (3) liberation of the toxin from the ballast of proteid bodies by intracellular fermentative processes, (4) solution in sterile distilled water, with subsequent addition of the necessary amount of salt.

After having proved that the pollen proteid of certain plants was the specific cause of hay-fever, I was enabled still further to elaborate my experiments by placing them on a quantitative foundation. The proteid is easily extracted from pollen by suitable salt solutions, from which it is obtained in pure condition by precipitation with alcohol or by dialysis, and dried. In this condition it retains its efficacy unimpaired for years.

Referring to my first convincing experiments on the etiology of hay-fever, it is only fair to point out that they did not correspond with the natural development of the hay-fever attack. This was more closely imitated by the following experiment. A hay-fever patient and a non-susceptible person (the control) stood in a large glass cupboard in which rye pollen were distributed. The patient developed an attack, the control remained free from symptoms. In this experiment however it was not possible to determine the number of pollen inhaled by the experimenters. The question had not as yet been satisfactorily solved whether during the hay-fever season the number of poisonous pollen present was sufficient to cause an attack. In this direction the experiments of Blackley mentioned previously had paved the way. By the use of a method suggested by Phoebus he had performed accurate counts of the pollen which adhered at different seasons to shides which had been rendered sticky with glycerine. My collaborators, especially: Liefmann ${ }^{2}$, found that at the time of the worst hay-fever attacks in the centre of the city of Hamburg no less than 250 grass

1 O. Kammann, “Zur Kenntnis des Roggenpollens und des darin enthaltenen Heufiebergiftes." Beitr. z. chem. Phys. u. Path. 1904, vol. v. p. 346.

2 Liefmann, “Ein Beitrag zur Frage nach der ätiologischen Bedeutung gewisser Pflanzenpollenkörner für das Heufieber." Zeitschr. f. Hygiene u. Infektionskrankheiten, 1904, vol. xLvir. p. 153. 
pollen settled in 24 hours upon a surface of one square centimetre, i.e. about 2,500,000 pollen upon a square metre. It was most interesting to note year by year how the first appearance of a few pollen in the air coincided with the time when the patients began to feel the first itching in their eyes; how the suffering increased with the number of pollen in the air; how on rainy days the pollen was absent on the slides although these were protected from the rain by suitable covers. In the beginning of June the grass pollen surpass in number all the other pollen in the air; from the third week of July they gradually disappear, but a few are found to linger until the end of July or even the first part of August. These results would appear to explain satisfactorily the periodic variations and the occurrence of isolated hay-fever attacks.

It was still necessary to gain an accurate estimate of the effect to be expected from a given number of pollen grains. Dr Kammann has found that about $40 \%$ of the organic substance of the grass pollen consists of proteids. $\mathrm{He}$ also found by enumeration that about 20 millions of rye pollen grains weigh one gramme. From these figures the toxicity of a single pollen grain was calculated. With exactly prepared solutions of the poisonous pollen proteid it was further possible to determine how many pollen grains were required in the different patients to produce mild, medium and severe attacks. We thus found, as was to be expected, considerable differences in the susceptibility of the patients. Normal persons were unaffected even by the instillation of concentrated proteid solutions into the eye or nose. The majority of hay-fever patients were affected by one drop $\left(=\frac{1}{20}\right.$ to $\frac{1}{30}$ c.c.) of a solution $1: 20,000$ to $1: 30,000$. But some patients were found susceptible to one drop of a million fold dilution. This amount corresponds to the contents of two or three pollen granules.

H. Liefmann has constructed an aeroscope with which apparatus he endeavoured to find out how many pollen grains were inhaled with one breath during the principal hay-fever season. Near a rye-field he found one breath to carry two or three pollen grains, but even in the centre of a large town 20 to 30 pollen grains were found in a cubic metre of air. Thus the question as to the quantitative conditions in hay-fever has also received a satisfactory solution. From the experiments already described the definite conclusion can be drawn, that the pollen proteid of certain plants, especially of all the grasses hitherto examined, is the cause of hay-fever.

In connection with these investigations, I have examined with my collaborators the pollen of 106 other plants-the result being negative 
although I tested particularly such pollen which had been stated by others to cause the symptoms of hay-fever. Besides the pollen of the 32 species of Graminaceae and Cyperaceae I have only found the following pollen to be toxic: honeysuckle (Lonicera caprifolium), Lily of the valley (Convallaria majalis), Polygonatum multiflorum, Oenothera biennis, rape (Brassica napus) and spinach (Spinacea oleracea) as well as a number of Composites.

When I was informed that in China hay-fever-like disease is observed at the time of flowering of Ligustrum vulgare, I examined its pollen and found them to be toxic. In S. W. Africa similar symptoms are observed when the grasses flower, the half-breed population being particularly affected. A European was forced to leave Africa at this season, his sufferings being intolerable, yet in Europe he remained quite healthy. Examination showed him to be unaffected by grass pollen. At the same time in S. W. Africa the acacias flower, and these have been suspected to be the cause of the disease. Yet this patient was not affected by the pollen of Acacia dicabata and of Robinia pseudacacia. Uhlemann has since found that S. W. African hay-fever is carried by the pollen of a species of Eragrostis. The extract of these pollen which he kindly sent me was tested on persons susceptible to European hay-fever; of these some were not affected, some only showed objective but no subjective symptoms, whilst others were affected both objectively and subjectively. Eragrostis belongs to the Graminaceae. This would therefore be the first instance where the pollen proteid of a grass did not influence European hay-fever patients. I an at present endeavouring to cultivate Eragrostis in Hamburg, in order to amplify the results obtained hitherto.

A disease of paramount importance is the autumnal catarr which begins in the United States about the first part of September and which also lasts about six or eight weeks. This autumn catarrh is reported to occur far more commonly in the States than the spring form of hay-fever. I have had the opportunity of testing a number of American patients. It was thus found that those patients who only suffer in the autumn are unaffected by the pollen proteid of grasses, but that they always react to that of golden-rod (Solidago) and of ragweed (Ambrosia). Of these composites a large number of species has been investigated, all being found active. The same patients react also to the pollen proteid of Chrysanthemum and Asters.

On the other hand, those American patients who only suffer from the spring form, not from the autumnal catarrh, are susceptible 
to the pollen of grasses, but not to those of golden-rod and ragweed.

A third group of patients in America suffer from hay-fever symptoms between the middle of May and the end of November. These unfortunate individuals react both to grass pollen and to the causes of autumnal catarrh. Golden-rod and ragweed belong to the commonest weeds in the United States. They are found not only in every meadow, field, wood- and road-side, but even in the towns they grow in any illkept streets and steps. In Europe they are absent. Golden-rod can be brought to flower with us. Its pollen does not disperse nearly so much as those of ragweed. All our endeavours to bring ragweed to flower here were in vain until 1911. In this year, remarkable for its excessive heat and drought, I was successful for the first time.

The results that $I$ have laid before you up to now can be regarded as further important arguments in favour of the specific pollen theory. There still remain several doubtful points requiring elucidation before the whole enigma of the disease is understood. One matter which is of the utmost importance is individual susceptibility.

\section{Individual susceptibility.}

The foregoing remarks have shown that at certain seasons everyone -including the inhabitants of large towns-is attacked by numerous pollen grains which settle upon the skin, the conjunctival membrane, which penetrate into the nose in breathing and into the mouth during speech. The great majority of mankind is totally unaffected by this pollen, only a small proportion suffer from the disease. The active pollen proteid is not therefore a poison in the ordinary sense of the word; it is a substance harmless to most human beings, and active only in persons possessing a certain degree of susceptibility. Hay-fever therefore depends upon an individual predisposition. This is a condition hardly met with in the case of ordinary poisons of the pharmacopoea. In infectious diseases it is already much more marked. If e.g. the cholera or typhoid microbes are disseminated throughout a town by the water supply, it is only a comparatively small proportion of the persons infected which acquire the disease. The explanation is that the cholera microbe-which only becomes fatal in consequence of its proliferation in the human body-does not find the conditions for its life and propagation in most persons. The further fact that only about one half of the cholera patients die of the disease may perhaps be 
explained in a similar manner by considerations of quantity. I do not however know a second instance of one substance proving absolutely indifferent to a part of mankind, whilst appearing as one of the most intense poison to. others. There is reason to believe therefore that the individual predisposition in hay-fever is something special.

One might assume the hay-fever poison to enter into the circulation in certain persons, viz. the hay-fever patients, but not in others. This no doubt occurs, as I was able to prove by the demonstration of immune substances in the blood, a result to which reference will be made later. It will only be necessary to mention here that such specific substances are ouly found in hay-fever patients soon.after the hay-fever season but have disappeared six months afterwards. On the other hand in the normal persons examined we never found such substances even directly after the hay-fever season. The gradual disappearance of the immune substances from the circulation is readily understood. We know from animal experiments that such substances appear in the circulation at certain intervals after the inoculation, and that they only. remain in the blood if the treatment is continued, but gradually disappear after its interruption. At first sight the demonstration of immune substances in the blood of hay-fever patients appeared as a satisfactory explanation of the disposition. But soon doubts arose. For when the investigations were continued, these immune substances were not found in other hay-fever patients; in the following year I was not even able to find them after the hay-fever season in the same patients who had previously given a positive result. 'It will be shown later on, that specific immune substances were not found even in patients or normal persons who had received. several subcutaneous injections.

The following is however a still more serious objection. A colleague susceptible to hay-fever who for many years assisted me in my. investigations with the greatest self denial, injected himself subcutaneously in . the fore-arm with a solution of grass pollen proteid. Within the next half hour very severe symptoms developed in the mucous membrane of eye, nose and mouth. He suffered from pain in the chest, 'expectorated a tough mucous sputum and perspired profusely. Respiration was accelerated and difficult, the pulse-rate quickened, the voice hoarse. Fifty minutes later urticaria developed all over the body. The results of the inoculation were still felt by the patient on the next day. At the site of injection considerable tumefaction occurred which remained for five days. The same symptoms have occurred repeatedly 
when I injected myself with hay-fever poison. Yet another colleague, not susceptible to the disease who injected the same quantity, reacted only with a slight tumefaction at the site of inoculation. The pollen proteid was not therefore poisonous for him. Many hundreds of animal experiments have again and again proved that the pollen proteid is not a poison in the ordinary sense of the word and that it is harmless even when injected directly into the blood circulation.

The permeability of the skin of hay-fever patients for this poison is different from the normal. Even in individual patients various reactions may be observed. In some patients the application of a drop of pollen proteid solution to the skin is followed within a few minutes by erythema. In other patients, who may in other respects be very susceptible, the skin proves refractory to the pollen solution.

Indirectly, these results can serve as a guide for the study of individual predisposition, for they enable us to approach the question whether hay-fever is to be regarded as a reaction of supersensitiveness. Before entering into this question I must deal with the older attempts to explain the hay-fever predisposition. This subject has, I believe, received a fairly exhaustive treatment in my monograph ${ }^{1}$ up to the year 1902. The details will not therefore require to be repeated here. It will suffice to mention briefly only such views which I have found still to influence several oculists and rhinologists although being in direct contradiction with the result of my experiments. The first point requiring mention is that all statistical enquiries have shown that hay-fever by no means depends upon certain constitutional diseases, e.g. gout. In fact only a small percentage of hay-fever patients show this diathesis. Many observers believed hay-fever to depend upon deviation or impermeability of the upper air passages. Others assume a local neurosis of the fifth cranial nerve leading to sensitiveness of certain mucous membranes. The incorrectness of such views is shown by my already mentioned experiments. Not only the entire skin of many patients reacts to the poison, but even the subcutaneous injection is followed by characteristic hay-fever attacks. Finally, the fact that the mucous membrane of the anus of hay-fever patients reacts to the pollen proteid, I believe to bave conclusively disproved all hypotheses based upon the assumption of a specific sensitiveness of a cranial nerve or a mucous membrane of the head.

Suggestion as has been shown plays an important part in the

1 Dunbar, Zur Ursache u. spezif. Heilung des Heufiebers, 1903. Verlag Oldenbourg, München.

Journ. of Hyg. xIII 
explanations of hay-fever disposition. I can treat it in common with the subject of the effect of certain odours, e.g. of flowers, cats, horses, etc. In order to obtain some evidence, I undertook the following experiment. A number of hay-fever patients received simultaneously a drop of a colourless and odourless fluid into the eye and the nose. Some reacted, others did not. None knew what had been administered. Then the reverse experiment was performed, and now those patients who had reacted at first showed no irritation and vice versa. The one fluid was normal saline, the other a solution of grass pollen proteid. None reacted to the former, all to the latter. Such experiments have been frequently repeated with different modifications and the results have always been consistent. It is therefore impossible to explain hayfever as due to suggestion or the like.

Hay-fever has been regarded as the result of higher civilisation. It is true that very few cases are observed in the labouring classes, and also that the greatest contingent of hay-fever patients is furnished by the Anglo-Saxon race, Germans, Englishmen and Americans. The disease occurs occasionally among the romanic and other peoples. In St Louis I saw a young negro, employed as a lift-boy, who suffered from hay-fever. Among the particularly susceptible Anglo-Saxon race the mental workers are specially affected. It has been stated that men are twice as liable to hay-fever as women, but this is not confirmed by accurate statistics. Frequently the disposition is reported to have followed mental overwork or great excitement, e.g. after examinations, in officers after the manoeuvres. Very often the disease has been found to be inherited. Most commonly it seems to have occurred during convalescence after a severe attack of influenza. Other severe affections, e.g. difficult labour, are definitely stated by some patients to have led to the hay-fever susceptibility.

Is the conclusion justified that hay-fever is the result of damage to the central nervous system? The view formerly held that hay-fever patients were particularly nervous, excitable persons, cannot be upheld in this generalisation. If it is due to any damage of the central nervous system, the effect is only evidenced by the hay-fever disposition. Hundreds of hay-fever patients have informed me that outside of the hay-fever season they are always healthy, and among such patients I have frequently found most phlegmatic natures.

Those idiosyncrasies which show some resemblance to hay-fever, e.g. the susceptibility of certain persons to strawberries, crabs, to iodine, antipyrine, bromides and quinine salts one is nowadays inclined to 
regard as supersensitiveness, i.e. as renaphylactic symptoms. Ten years ago I considered the possibility of the hay-fever disposition belonging to this class of conditions. E. v. Behring ${ }^{1}, K_{\text {norr }}^{2}$, and others had already stated that certain animals which had received a sub-lethal dose of diphtheria toxin, subsequently showed excessive reactions with far smaller doses. The supersensitiveness of tuberculous patients to the proteids of the tubercle bacillus, observed by $\mathrm{R} . \mathrm{K}_{\mathrm{chh}}{ }^{3}$ in 1890 , is also one of these phenomena. But at that time the regular occurrence of this phenomenon had not yet been recognised. Since then an almost boundless literature has developed with regard to this subject. It is safe to say that at the present time the anaphylactic processes are predominant in all research on experimental therapeutics. It is characteristic of anaphylaxis that in no case has the occurrence of anti-bodies been observed to the anaphylactic toxin which was shown by Friedberger to be the cause of these symptoms. A further important observation is that this supersensitive condition can be transferred by injection of the blood serum of anaphylactic animals or human beings (passive anaphylaxis). Lastly, that after recovery from the anaphylactic shock an anti-anaphylactic condition develops. Any attempt to regard the hay-fever disposition as an anaphylactic condition must therefore take into account these three facts.

As regards passive anaphylaxis, I have injected the serum of hay-fever patients intravenously into guinea-pigs. Twenty-four hours later this was followed by an intravenous injection of rye pollen proteid. Both in these cases and even where I injected the serum of guinea-pigs, which had received repeated injections of pollen proteid, into other guinea-pigs, and followed this by injection of pollen proteid, I only noted mild, transient convulsions and a fall of their temperature to $36 \cdot 1^{\circ} \mathrm{C}$. These results are not in favour of the anaphylactic hypothesis.

The hay-fever patient himself does not become anti-anaphylactic after a hay-fever attack. The decline of hay-fever on certain days is more easily explained, as we have seen, by a reduction in the quantity of pollen as it coincides with the rainy days. All observers appear to be agreed that the hay-fever patient does not become less, but rather more sensitive after an attack.

One of my collaborators has stated that he had experimentally

1 v. Behring and Kitashima, Berliner klin. Wochenschr. 1911.

2 Knorr, Habilitationsschrift, Marburg, 1895.

3 Koch, "Weitere Mitteilung über ein Hẹilmittel gegen Tuberkulose." Deutsche med, Wochenschr. 1890. 
applied pollen proteid to his eye thousands of times, yet the minimum dose was not altered. I have observed the like hundreds of times.

All clinical observations agree that in hay-fever anti-anaphylaxis does not occur, and that therefore the hay-fever disposition is not in this respect comparable with anaphylaxis.

In the third point also hay-fever does not coincide with our present definition of anaphylaxis, for it is possible, as will be shown subsequently, to prepare a true antitoxin against pollen proteid.

On the other hand all my experiments and considerations are opposed to the view that the hay-fever disposition is identical with anaphylaxis. They are rather explicable by an opposite hypothesis.

Other considerations must also be borne in mind. The anaphylactic hypothesis is based on the following supposition: In some way the hay-fever patient receives into his body a considerable amount of pollen proteid. He would thus become sensitised, i.e. rendered sensitive to the subsequent injection of pollen proteid. Yet I have repeatedly observed that persons living in Germany who have never been in America and thus never came into contact with the pollen of golden-rod or ragweed, developed hay-fever at the first contact with such pollen proteid. On the other hand, I found that normal persons never develop hay-fever after the subcutaneous injection of grass pollen proteid, although the dose injected was a multiple of what these persons could have absorbed in a natural manner in the course of many years. Previous to the hay-fever season of 1912 I injected a normal individual at intervals of five days with such quantities of hay-fever poison as they could never have absorbed under ordinary conditions, quantities which in the hay-fever patient would have led to alarming symptoms. Although this person daily took long walks through meadows in full flower during the hay-fever period, he has not shown the slightest signs of the disease.

Besides, the results of the injection of the toxin in hay-fever patients to which I shall refer later, are decidedly opposed to the view that hay-fever could be an anaphylactic condition.

Yet even if we should be able to characterise the hay-fever predisposition as a sensitisation comparable to anaphylaxis, we should not have obtained a satisfactory explanation of the individual susceptibility. For we should still have no explanation of the fact that normal persons cannot be rendered susceptible even by the subcutaneous injection of pollen proteid. The normal person has not therefore the capacity of reacting to this proteid, whilst the hay-fever patient is endowed with 
it to a considerable degree. We must patiently proceed with experimental research and endeavour somehow to obtain a key to the explanation of these phenomena.

Further experiments to elucidate the hay-fever disposition appear to be called for because this is the only disease with which we can safely experiment on human beings, and because the results thus obtained can at once be used in the explanation of other toxic and infective diseases.

A year ago I showed that during the hay-fever period the serum of hay-fever patients has a different influence upon erythrocytes to that of normal persons. It haemolysed e.g. the red blood corpuscles of guineapigs, rabbits and sheep. Six months later the serum of the same patients had quite or almost lost its haemolytic effect upon these blood corpuscles, but where haemolysis did not occur, we observed agglutination. These experiments were continued by Dr Gaehtgens with monkeys. He found that the serum of a monkey before the injection of pollen proteid did not influence the erythrocytes of rabbits and guinea-pigs and only slightly agglutinated those of sheep. Ten days after the injection of pollen proteid the red blood corpuscles of rabbits were energetically agglutinated, those of guinea-pigs slightly haemolysed, whilst those of sheep were not influenced. A control monkey injected with horse serum however showed a similar reaction. Thus the path which we had hoped to find again seemed lost. I attach the greatest value to the further continuation of these experiments.

In this connection I may mention a series of experiments which were also begun several years ago. They were based upon the observations of Preston Kyes that cobra venom is activated by lecithin so as to dissolve red blood corpuscles to which it otherwise proved inactive. Similar experiments were undertaken in this direction with pollen proteid, at first without any valuable result. Dr O. Kammann has since been investigating these phenomena with the following results :

If (1) washed blood corpuscles are treated with pollen toxin, they are not affected. The same is the case if (2) the corpuscles are treated first with lecithin and then with pollen toxin. But if (3) pollen toxin is mixed with washed ox blood corpuscles, and lecithin added about ten minutes later, haemolysis results. The same result is obtained if (4) the blood corpuscles are treated with pollen toxin, then separated from the fluid and taken up in a lecithin solution. These experiments will shortly be published in detail. Possibly they have a bearing upon the questions considered previously. It is certainly worth while to 
enquire whether the individual susceptibility of the hay-fever patient can be due to the presence of greater quantities of lecithin in their blood than are in the blood of normal persons. Proceeding from the idea which I firmly believe in, that hay-fever is due to damage of the central nervous system, it is possible to advance one step further and to assume that such damage might be due to an excessive secretion of lecithin into the blood. The interesting discovery has recently been made by Dr Kammann that the pollen toxin contains a lipolytic ferment; this has suggested to him that possibly this secretion of lecithin might be referable to the pollen toxin. Still, in all such hypotheses we are brought back to the postulate that normal persons ought also to be influenced by solutions thus prepared. All investigations undertaken in this direction have hitherto had no result. Therefore even these most recent experiments do not afford sufficient reason for me to depart from my view that we cannot at present explain the enigma of hay-fever disposition.

In this connection it will be worth while to refer to the susceptibility of certain persons to horses, cats and other animals. I have mentioned that several genuine hay-fever patients were found to suffer from similar symptoms outside of the hay-fever season, as soon as they entered a stable or circus, or only rode in a horse-drawn vehicle. According to one author who looks upon hay-fever as an anaphylactic condition the patients are so highly sensitised towards horse serum, that the merest trace of skin excretion would suffice to produce an anaphylactic attack which may resemble an attack of hay-fever. In order to put this view to the test $I$ undertook the following experiment. A lady who was affected with hay-fever symptoms whenever she entered a stable or circus or drove in a carriage was unaffected by the application of scales removed from horses with the curricomb. This lady was especially suited for such experiments, because she showed no trace of nervous or hysteric tendency. Acting upon my suggestion she visited a horse show after having treated her eyes and nose with pollen antitoxin derived from a horse. Although she was present for hours at the show, not the slightest symptom of irritation was noticed. In this, as in several other cases, I was able therefore to prevent the irritation caused by horses by means of a preparation rich in horse proteid. This critical experiment will have to be considered in future by authors desirous of propounding new hypotheses for the idiocyncrasies described.

The same patient stated that she was attacked by hay-fever as soon 
as she touched a cat. The following experiments confirmed her statement. I let her stroke the fur of a cat a few times and then touch her cheek with her hand. Neither hand nor eye showed any symptoms. The eye-which had been kept closed while she touched her cheekremained unaffected for ten minutes. I was prepared to disbelieve her statement, but the lady definitely affirmed that the attack would come. After 15 minutes she felt itching in the eye corresponding to the cheek she had touched. At the same time the conjunctiva. of this eye began to be congested. Within the next few minutes congestion increased, the caruncula became dark red, the itching and burning became worse. The patient asserted that if we allowed the attack to proceed it would develop into a severe hay-fever attack. As soon as pollen antitoxin was administered to the eye, the subjective symptoms were improved, and soon after the congestion declined.

Hairs cut from the same cat were extracted with ether, alcohol and normal saline solution. These extracts proved inactive. I then asked my patient to touch the hairs after they had been kept for 24 hours, also without any effect. But when she touched hairs that had been cut off five minutes before a positive result was obtained. Other substances had meanwhile been examined, but all were found to be inactive, although I had throughout endeavoured to produce an effect by means of suggestion.

Since it was possible that traces of saliva adhering to the hairs might contain the active principle, I collected some saliva by allowing the cat to bite upon a cotton wool plug saturated with milk. After touching this plug the lady had a typical attack. I am therefore convinced that we are dealing here with a very marked specific idiosyncrasy against cat's saliva. Further experiments in this direction are being conducted. The case appears particularly important to me because such idiosyncrasies to my mind are very nearly related to hay-fever, for otherwise it would be impossible to influence them favourably by pollen antitoxin.

It will be evident from the foregoing remarks that the problem of individual hay-fever susceptibility has not yet received a satisfactory solution. It is far simpler to decide in any given case whether the disease is hay-fever or not.

The observations already described regarding the irritative action of the pollen proteids of certain plants upon the mucous membranes of hay-fever patients have been employed from the first for purposes of diagnosis. 


\section{The diagnosis of hay-fever.}

It has been stated that a hay-fever patient reacts with symptoms of the disease after the instillation of a drop of 1 in 20,000 pollen proteid solution, whilst normal persons are not affected by solutions containing one per cent. or even more of the proteid. This is a simple, certain and conclusive means of diagnosing hay-fever, a test the like of which cannot be applied to any other disease.

By this test it is even possible to determine whether the patient is subject to the European or the American autumn fever, or both forms. It is thus possible to decide absolutely whether the patient is the victim of nervous coryza or other symptoms resembling hay-fever. We can ascertain whether persons who believe themselves to be sensitive to the odour of cats, horses, etc., judge their affections correctly or are subject to genuine hay-fever.

Much confusion as to the inefficiency or uselessness of hay-fever remedies would be avoided if the physician regularly controlled his diagnosis in a scientific manner in every case suspected to be hay-fever. Messrs Schimmel \& Co. in Miltitz have readily undertaken to furnish any physician with the toxin free of charge. It is supplied weighed out for use in a very convenient outfit and is called the "hayfever diagnostic."

In this connection I may be permitted to remark that the whole method of conjunctival diagnosis or ophthalmo-reaction which is so commonly practised nowadays is the outcome of my hay-fever reaction, although it is generally associated with other names. Ten years ago it was also shown by my investigations that the hay-fever poison produces irritation in some patients when applied to the uninjured cutis.

\section{Experiments to obtain specific immune substances, particularly an antitoxin.}

The experiments already described will have proved that the specific hay-fever poison is identical with or at least inseparable from a proteid.

Whether there was any chance of obtaining a specific antitoxin was doubtful at the beginning of our experiments. Behring ${ }^{1}$ had, it is true, shown the possibility for tetanus and diphtheria, of obtaining specific antitoxins by the use of the specific bacterial toxins. Ehrlich ${ }^{2}$ too had prepared antitoxius to the toxic proteids derived from certain higher plants (abrin, ricin). The pollen proteid of grasses is not a poison comparable to those $I$ have mentioned, since it is inactive towards most men and animals. It is toxic only for a small fraction of human

1 Behring and Kitasato, “ Über das Zustandekommen der Diphtherieimmunität und der Tetanusimmunität bei Tieren." Deutsche med. Wochenschr. 1890, No. 49.

2 Ehrlich, "Experimentelle Untersuchungen über Immunität." Ibid. 1891, Nos. 32 and 44. 
beings. Further, it has been shown by animal experiment that it does not belong to proteids of high avidity: thus e.g. the proteids of fish-roe when injected into animals lead to a far more energetic formation of anti-bodies (precipitins, cytolysins) than the pollen proteid, and are thus shown to possess a far higher degree of avidity.

Although the conditions did not appear favourable, my first experiments with rabbits in the spring of 1902 led to unexpectedly promising results. The serum of rabbits which had received several intravenous injections of pollen proteid (1) in vitro influenced and altered the proteid in such manner as to render it inactive to hayfever patients. It was also possible (2) by the application of this immune serum promptly to remove the irritation induced in hay-fever patients by the pollen toxin. Finally (3) is was proved that instillation of the poison into the conjunctiva had no result, if the immune serum had been instilled previously. This success encouraged me to undertake inoculation experiments with larger animals, viz. with goats and horses. Goats almost always proved refractory to the pollen proteid, and even after prolonged treatment most of them produced no antitoxin. Only one of them fainted after every injection and finally died immediately after an injection in consequence of its supersensitiveness, or, as we should now call it, from anaphylactic shock. Such occurrences I now believe to be preventable, since we have given up injecting the crude pollen extract, and inject the pollen proteid after removal of all the non-specific ballast (Kammann). Horses also showed very varying reactions to the pollen toxin. I am not sure whether it was only a chance that among the comparatively large number of horses which I inoculated, common farm horses proved refractory, whilst well-bred animals, particularly broken-down racers, reacted severely. It seemed quite possible that the exciting work required from such animals might have rendered them susceptible to the poison just as we imagine civilisation to have affected man. This can only be decided by an extensive series of experiments. I would note however that it was our constant experience that horses which reacted to pollen toxin always did so at the first inoculation. Further injections did not increase their susceptibility; on the contrary they tolerated considerably greater quantities of the poison at a later stage of treatment. Thus the initial dose often caused symptoms of such severity that the consulting veterinary surgeon expected the animal to succumb. Yet in the course of treatment they received as much as 30 times the original dose without showing any symptoms. Apart from fever, profuse perspiration, 
convulsive trembling and loss of appetite, the most noticeable feature was the formation of urticaria-like wheals. The oedematous swelling at the site of injection in some horses had a diameter of 50 to 75 centimetres. In other cases the first injection was followed by an eruption of wheals the size of a walnut all over the body of the animal; subsequent injections of larger quantities of the toxin were tolerated without the formation of such eruptions.

A somewhat inaccurate critic has brought a good deal of confusion into the hypotheses of hay-fever by the assertion that the horses become more susceptible after the injection, and later on react to smaller doses, but do not tolerate increased amounts. This assertion disagrees with all our observations. All hypotheses and conclusions founded on it are therefore baseless. One of these fallacious conclusions was that it would be impossible to prepare a specific antitoxin for pollen toxin. In some instances it is true highly immunised horses are reported to have shown congestion of the conjunctiva after instillation of the pollen proteid. I have never witnessed such occurrences, but their possibility must be admitted in view of the observation by Walther ${ }^{1}$ of hay-fever symptoms in a horse.

Certain rabbits and horses therefore are exceptionally well suited for the preparation of a specific pollen antidote, or antitoxin. The existence and potency of such antidote can only as yet with certainty be shown by clinical methods, or by combined examination in vitro and in the body. Precipitins I have never observed except in the serum of hay-fever patients where a very weak though unmistakeable reaction was noted. In numerous rabbits no trace of precipitins could be demonstrated in spite of numerous injections of pollen. Only once a turbidity was observed, but this $\mathrm{I}_{\text {proved }}{ }^{2}$ to be non-specific. In spite of the contrary assertion of Magnus and Friedenthal ${ }^{3}$ I must therefore still adhere to the statement that rabbits do not form precipitins after injection of pollen. These interesting experiments are however being continued. In horses also we do not as a rule observe precipitins. A turbidity was only produced by the serum of one animal ${ }^{4}$. which soon after died of tetanus.

It is interesting 5 , in view of this observation, that the male sexual

1 Walther, "Über das Vorkommen des Heufiebers beim Pferde." Berlin. Tierärztl. Wochensch. 1911, p. 818.

2 Dunbar, “Über das serobiologische Verhalten der Geschlechtszellen." Zeitschr. fïr Immunitätsforschung, 1910, vol. vir.

3 Magnus and Friedenthal, Ibid. 1910, vol. v. $\quad 4$ Dunbar, Ibid. 1910, vol. vi.

5 Dunbar, Ibid. 1910, vol. vi. 
cells of fishes and other animals also do not induce the formation of precipitins.

Peculiar conditions are also found with the method of complement deviation. Rabbit sera were obtained which gave a complete positive reaction with a 50,000 fold dilution of pollen proteid. Yet in horses, sera of high toxin-neutralising potency only showed a trace of deviation with proteid solutions diluted 1 in 10 or 1 in 100 . Sera showing such differences in complement deviation may however possess the same potency in neutralising the corresponding pollen poison for the eye of the hay-fever patient.

The potency of a serum cannot therefore be measured by the complement deviation or the precipitin test alone. The former method might incidentally serve to show an increase in the amount of immune substances.

Since all my endeavours to find an animal susceptible to the pollen toxin have failed hitherto, we can at present only ascertain the effect of the pollen-immune serum in the hay-fever patient. In them however the reaction is so definite and precise that this test is one of the most delicate biological methods known to me. Other antitoxins are tested by the criterion of the death or survival of the animal. But in testing pollen antitoxin the hay-fever patient can judge of the existence of the slightest trace of subjective irritation, whilst the investigator watches whether the conjunctiva is congested or remains unaffected. An objectively visible reaction is caused as we have seen by minute quantities of free toxin. In most patients $\overline{2} \frac{1}{\delta} \overline{0}$ milligramme of the pollen proteid suffices to produce congestion and marked oedema of the conjunctiva. This reaction as will be shown subsequently, usually spreads to the nasal mucous membrane and causes convulsive sneezing fits. In very susceptible patients $\frac{{ }_{4}}{400 \sigma \sigma}$ milligramme of the proteid suffices to cause the same symptoms. Of the proteid purified according to Kammann's method one drop of a solution 1 in 300 millions ( $\left(_{\bar{y} \sigma 00 \delta \bar{l}}\right.$ milligramme) still caused subjective symptoms in particularly sensitive individuals, the result being controlled by instillation of normal saline which had no effect. These quantities are so minute as to be immeasurable with the most delicate scales, the reactions are therefore far more delicate than those employed in the finest chemical methods. Further, the same patient after many repeated reactions reacts with almost absolute constancy. Privatdocent Dr Carl Prausnitz who for years assisted me in the most self-sacrificing manner in my hay-fever work recently stated ${ }^{1}$ that he had carried out thousands of such reactions upon himself without observing any noticeable change in his susceptibility.

Kammann and Gaehtgens ${ }^{2}$ have recently found as the result of accurate investigation that a patient who usually reacts to a dilution $1: 400,000$ may occasionally react only to a drop of a 200,000 fold dilution.

1 Prausnitz, “Heufiebergift und Heufieberserum." Habilitationsschrift, Jena, 1912.

2 Kammann and Gaehtgens. "Experimentelle Untersuchungen über die Bindung von Pollentoxin und Antitoxin.” Zeitschr.f. Immunitätsforschung, 1912. 
In such experiments we have always found the toxic effect to be localised. It never spreads from one eye to the other. But it is washed down from the conjunctiva into the nasal cavity through the nasal duct; thus in all relatively severe conjunctival reactions similar irritation follows in the corresponding side of the nose, but never on the other side. If the toxin is instilled immediately into the nasal cavity, its effect is frequently seen in the posterior pharyngeal part, and some patients even feel irritation in the deeper air passages. Occasionally the toxic effect can even spread in this direction from the conjunctiva down into the pharynx, but it is always confined to the corresponding side.

These observations are the foundation on which I have based the examination of the antitoxic value of pollen anti-sera.

The first thing was to determine the patient's susceptibility, i.e. the limit of stimulation at which subjective and objective hay-fever symptoms are manifest. If e.g. a hay-fever patient did not react objectively to a grass pollen proteid solution $1: 30,000$, whilst congestion of the conjunctiva was promptly produced by instillation of a drop of $1: 20,000$ solution, the potency of the serum was determined as follows. Mixtures of the active toxin solution were prepared $(a)$ with normal horse serum, $(b)$ with the immune serum to be tested. One mixture was instilled into the right, the other into the left conjunctival sac. The mixture containing normal serum was always found to be as active as the pollen toxin alone. But the mixture with immune serum produced no symptoms if the correct proportion was found. Dr Prausnitz, to whom I am indebted for his assistance in these investigations, suggested an improvement of this method which I have regularly employed. The procedure is therefore as follows.

In order to have definite results the toxin solution is used in double the necessary concentration. If the patient shows an objective reaction with a solution $1: 40,000$, a solution $1: 10,000$ is prepared. If the serum is supposed to be " 40 fold," a dilution $1: 20$ is made. Equal parts of these solutions being mixed, the toxin is present in 20,000 fold, and the serum in 40 fold dilution. The mixture is kept for 30 minutes at $37^{\circ} \mathrm{C}$. and then tested on the patient. If the serum is really 40 fold, objective or subjective symptoms occur. If the patient feels slight itching, but no objective signs are observed, the serum is registered as "bordering on 40 fold." If objective symptoms are seen, the serum is next tested for 30 fold potency, and so on. 
The nature of the hay-fever poison and antidote.

For hay-fever patients the proteid of active pollen is a toxin comparable to abrin, ricin, diphtheria toxin, etc. The correctness of this view I have never questioned. But other authors have asserted repeatedly that the pollen proteid is not a genuine toxin. This assertion is based partly upon confused and erroneous views of the facts which had been experimentally proved. My horses were stated after inoculation of pollen toxin to have become not immune, but on the contrary supersensitive. This has already been shown to be a misconception. The only objection which hitherto appeared to be at least partially justified was that according to experiments of Prausnitz ${ }^{1}$ the curve of neutralisation of toxin and antitoxin was different from that observed with diphtheria and other genuine toxins. This objection is however not justified since Kammann's ${ }^{2}$ re-examinations showed that with pollen toxin also the curve of neutralisation follows the law of multiples, exactly as with diphtheria toxin. In view of the importance which has been attached by certain authors to this curve of neutralisation, Kammann's technique and results are given in detail.

Results after 3-4 hours' contact of toxin and antitoxin at $37^{\circ} \mathrm{C}$.

Minimal active dose : $0.008 \mathrm{mg} .=1$ drop of toxin solution $1: 5000$.

Amount of toxin
$0.02 \mathrm{mg}$.
0.4
0.8

Amount of antitoxin
$0.2 \mathrm{mg}$.
$4 \cdot 0$
$8 \cdot 0$

Result
neutral
trace
neutral

The contrary results of Prausnitz are explained by Kammann to be explicable by the use of too small doses of toxin, and by an insufficient time having been afforded to the antitoxin to complete the chemical neutralisation of the toxin.

Kammann's experiments were performed with ambrosia-toxin. I consequently requested Drs Gaehtgens and Kammann to carry out an extensive series of experiments with grass pollen toxin upon several hayfever patients. These experiments which were throughout performed

1 Prausnitz, “Zur Natur d. Heufiebergiftes u. seines spezif. Gegengiftes." Berl. klin. Wochenschr. 1905. Prausnitz, "Heufiebergift u. Heufieberserum." Habilitationsschrift, 1912, Jena.

${ }^{2}$ Kammann, "Das Heufieber u. seine Serumbehandlung." Berl. klin. Wochenschr. 1906. 
under my control and supervision had a decisive result, as will be seen from the following table ${ }^{1}$.

To explain this table a few remarks are required. The smallest dose of poison causing subjective and objective symptoms was designated " 1 T." Its value varies according to the patient. The details being given in the paper published by these authors. Although the different patients thus required different amounts of toxin, yet the necessary quantities of antitoxin were always the same. This is explained by the consideration that a " 40 fold" serum always proves of this strength no matter on what patients it may be tested, even though the minimal toxic dose was very different. Thus in employing the multiples indicated in the table, considerable differences occurred in the amount of toxin which had to be given to different patients. In case I, e.g. the 80 fold multiple was $\frac{1}{75} \mathrm{mg}$. toxin, because the minimal toxic dose was $\frac{1}{6000} \mathrm{mg}$. In case IV the same multiple was only $\frac{1}{3} \frac{1}{75} \mathrm{mg}$. because the minimal dose was $\frac{1}{30000} \mathrm{mg}$. This paradoxical observation has proved correct throughout this series of experiments. If in the different patients the dose was increased only slightly above the dose of toxin thus determined, neutralisation was not obtained with these multiples.

" $5 T$ " in the second column means five times the minimal toxic dose, " $10 T$ " ten times the minimal dose, etc.

" $1 A$ " designates the amount of antitoxin required to neutralise $1 T$. With the antitoxin employed it was always $\frac{5}{6} \mathrm{mg}$. and with the 80 fold multiple in all cases $66_{3}^{2} \mathrm{mg}$.

By this explanation the following table is readily understood. It shows that a toxin dose up to $80 \mathrm{~T}$ could be completely neutralised by $80 \mathrm{~A}$. Only in some cases did a border reaction occur with the lower multiple, i.e. the patients stated that they felt a little itching, without the occurrence of objective symptoms.

\section{Experiments upon the ratio of neutralisation existing between pollen toxin and antitoxin.}

\begin{tabular}{|c|c|c|c|c|c|c|c|c|}
\hline \multirow{2}{*}{$\begin{array}{c}\text { Designation } \\
\text { of patient }\end{array}$} & \multirow{2}{*}{\multicolumn{2}{|c|}{$\underset{\text { dose }}{\text { Minimal toxic }}$}} & \multicolumn{6}{|c|}{ Multiple tested } \\
\hline & & & $1 \mathrm{~T}+1 \mathrm{~A}$ & $5 T+5 A$ & $10 \mathrm{~T}+10 \mathrm{~A}$ & $20 \mathrm{~T}+20 \mathrm{~A}$ & $40 \mathrm{~T}+40 \mathrm{~A}$ & $80 \mathrm{~T}+80 \mathrm{~A}$ \\
\hline $\mathrm{Ca}$ & $\frac{1}{\delta 0 \delta \sigma}$ & toxin & $0^{*}$ & 0 & 0 & 0 & 0 & 0 \\
\hline II Chr & 30000 &, & 0 & $0-\mathrm{G}+$ & 0 & $0-G$ & 0 & 0 \\
\hline III Kl & Г2 $\frac{1}{800}$ & ", & 0 & 0 & $0-\mathbf{G}$ & $0-G$ & 0 & 0 \\
\hline IV $\mathrm{Ti}$ & $30 \frac{1}{300}$ & , & 0 & 0 & $\underset{\text { tested }}{\text { not }}$ & $\begin{array}{c}\text { not } \\
\text { tested }\end{array}$ & $0-\mathbf{G}$ & 0 \\
\hline Vö & $24 \frac{1}{\partial \sigma 0}$ & ", & 0 & $0-\mathbf{G}$ & 0 & 0 & 0 & 0 \\
\hline
\end{tabular}

* $0=$ complete neutralisation.

$+0-G=$ boundary reaction (subjective symptoms, but no objective signs).

1 Kammann and Gaehtgens, "Experimentelle Untersuchungen über die Bindung von Pollentoxin und Antitoxin." Zeitschr.f. Immunitätsforschung, 1912. 
The difference between these results and those obtained by Prausnitz is of considerable practical importance, since according to Prausnitz' curve the specific antitoxic treatment of hay-fever patients would hardly appear promising. For it is shown by his curve that-assuming his results to be correct--even relatively small amounts of toxin could hardly be neutralised under ordinary conditions of practice. According to Prausnitz, $2 T$ would require $3 \cdot 8 \mathrm{~A}$, but $5 T$ would need $125 \mathrm{~A}$. Yet according to our most recent experiments $2 T$ requires $2 A ; 5 T-5 A$, $60 \mathrm{~T}-60 \mathrm{~A}$.

This agrees entirely with the satisfactory clinical result obtained with the antitoxin. My views have been further confirmed by experiments performed on man, which I shall discuss later on. Although this question would appear to be definitely decided by the experiments just described, I will mention, for the sake of completeness, a few different hypotheses contained in our recent literature.

The view has been expressed that pollen toxin is an "endotoxin," i.e. a substance which is not in itself poisonous but which contains a specific poison. According to this view the hay-fever patient would liberate this toxin by means of a special solvent property of his secretions, and thus develop the symptoms of the disease; on the other hand normal persons would remain unaffected, their tears not having this power of liberating the poison. You are doubtless aware that Friedemann ${ }^{1}$ and Friedberger ${ }^{2}$ have been able in vitro to liberate anaphylactic toxin from substances devoid of any poisonous action, e.g. rabbit's blood or sheep's serum. By employing Friedberger's technique I was able to obtain in vitro from pollen proteid with pollen antitoxin and complements, a poison which kills guinea-pigs with the phenomenon of the anaphylactic shock. But this observation cannot be considered as a proof of the endotoxin hypothesis. For this poison did not cause hay-fever symptoms in normal persons. Further, it could not be regarded as a specific poison, because it was also obtained when the specific antitoxin was replaced by normal horse serum. It was even possible to prepare an intense poison for the guinea-pig by merely adding normal guinea-pig's blood to the pollen proteid.

C. Prausnitz ${ }^{3}$ has propounded a different explanation of the nature of the hay-fever poison and antidote. According to his view, the hayfever disposition is due to the presence in the hay-fever patient of a very small amount of amboceptor specific for pollen. The pollen proteid coming in contact with the mucous membrane is partially

1 U. Friedemann, "Weitere Untersuchungen über den Mechanismus der Anaphy. laxie." Zeitschr. f. Immunitätsforschung, 1909, vol. II. p. 591.

2 E. Friedberger, "Weitere Untersuchungen über Eiweissanaphylaxie." Ibid. 1910, vol. Iv. p. 636.

3 Prausnitz, “ Heufiebergift u. Heufieberserum.” Habilitationsschrift, Jena, 1912. 
decomposed by the joint action of such amboceptor and complement; in the further course of events this decomposition would end in the formation of non-toxic substances. Given a sufficient amount of amboceptor, this process would run so rapid a course that the intermediate toxic substance has no chance of coming into action. Thus my specific pollen antitoxin would only influence the hay-fever attack because it adds sufficient amboceptor so that the intermediate poison is prevented from acting.

This hypothesis I do not agree with for the following reasons. The pollen toxin is thermo-resistant, pollen antitoxin is not. If a neutral mixture of the two, which does not affect hay-fever patients, be heated for half an hour to $75^{\circ} \mathrm{C}$, the unstable antitoxin is destroyed, but not the toxin. If such a heated mixture is applied to the eye of a hay-fever patient, it causes symptoms of the disease. Thus, the poison is not decomposed by the antitoxin but it only forms a chemical compound with it, from which it was recovered in active form.

Such and similar considerations have firmly convinced me that pollen toxin and antitoxin belong to the class of genuine toxins and antitoxins, like the diphtheria toxin and its antidote. To my mind they act and combine according to the same laws as the diphtheria toxin and its antitoxin.

\section{The present state of our knowledge of hay-fever.}

\section{Treatment.}

Th. Albrecht declares that ten years ago every physician had his own hay-fever hypothesis. From my own experience I may add that every hay-fever patient also had an hypothesis of his own, which as a rule was most complicated. According to the very detailed information which I have received many patients have employed ten or more hay-fever remedies simultaneously or successively. Every new drug is taken up by the hay-fever patient and enthusiastically recommended to others. For usually he does not hear of it until near the end of the hay-fever season; as soon as he begins to use the remedy, the disease naturally ceases, and he concludes that this is due to the remedy used. Next spring brings the inevitable disappointment. Thus one remedy after another is soon forgotten, but they all reappear, under fresh names. The only lasting drugs are the narcotics, e.g. cocaine, adrenaline, anaesthesine, morphine, etc. I need waste no words as to the dangers which follow the repeated use of narcotics. In addition adrenaline and anaesthesine 
as well as the numerous preparations embodying these substances produce in many hay-fever patients symptoms even more intolerable than the disease itself.

I have myself so far as possible tried all the remedies which have been repeatedly recommended during the last ten years, but in every case without any result; nor was there any theoretical support for the remedial action asserted. The outcone of my own experience agrees with the result of careful study of the case histories of hay-fever at my disposal. I have mentioned that no success could be expected from any of them and that not even chance has yet provided us with an efficient chemical preparation. Every conscientious physician must warn his patients against the use of narcotics particularly in hay-fever. Therefore the medicines and modes of treatment based on their use need not be entered into.

In over a thousand histories which have been communicated to me by hay-fever patients, the application of caustics, the cautery, chisel and saw in the nose play an important part. Yet all these histories end with the remark that not one of these painful proceedings had benefited the patient. Ten years ago Zarniko declared that such operative treatment baving proved useless would cease as soon as a specific treatment had been discovered. This conclusion is as logical and concise as could be desired, yet from a consideration of the histories at my disposal I cannot but presume that even nowadays hay-fever patients are freely operated upon.

It has been shown that the active pollen proteid is a substance of a very high degree of specificity. Thus a proteid causing hay-fever with one patient (e.g. grass pollen in Europeans) is inactive in others (patients suffering from American autumnal catarrh). On the other hand, European patients are usually not affected by ragweed proteid. With the complement deviation test I found ${ }^{1}$ that this specificity of the different proteids is manifested also in their haemolytic effects, the grass pollen proteids reacting quite differently to those of golden-rod and ragweed. Under these conditions it would indeed be a particularly lucky chance which gave us an efficient remedy: for such a substance would either require to have an affinity to the active proteid-and thus to neutralise or destroy it_or it would have to remove the factors underlying that individual susceptibility which also was shown to be specific.

1 Dunbar, "Ueber das serobiologische Verhalten der Geschlechtszellen." Zieitschr. f. Immunitätsf. 1910, vol. vi.

Journ. of Hyg. xiıI 
Since the discovery of the etiology of hay-fever it has been evident that there are only three ways by which the disease can be successfully treated.

The first is to search for localities free from the specific agent; the second to employ apparatus to protect the eyes, nose and mouth of patients from contact with such agents; the third to immunise the patient actively against pollen toxin or to use a specific antidote.

The first way is successfully employed every year by a number of patients. The second also is stated to give satisfactory results.

That hay-fever patients remain free from the disease if they live in districts where the active pollen does not exist, is evident from what has been said about the etiology. Thousands of patients find relief and cure of their troubles at sea, on islands or in barren mountain districts. The German Hay-Fever Association recommends Heligoland, in the United States patients retire chiefly to Fire Island, Long Beach Island, the White Mountains, the Green Mountains, the Adirondacks, etc.

Various investigators have recommended masks or air filters to be fixed in the nostrils. Verworn recommends the application of a neutral fat (bormelin) to the nasal mucous membrane and the introduction of a cotton wool pledget. He has succeeded in keeping free from attacks by this sinple technique. The principle of the treatment is due no doubt to the filtration of the pollen by the cotton wool, for it has been conclusively proved that all non-specific ointments are of no lasting use. On the whole, masks and filters do not appear to have found much favour, the majority of patients being doubtless inconvenienced by such appliances. Neither method of course leads to a permanent cure.

With experiments on active immunisation I shall have to deal later on and will first consider the subject of passive inımunity.

The efficacy of pollen antitoxin, "Pollantin," having been experimentally decided, there was reason to hope that it would act curatively as well as prophylactically. Soon after the introduction of the specific antitoxin, there followed another serum preparation called "Graminol." In connection with this preparation it was asserted that an efficient serum could be obtained normally from ruminants, e.g. cattle, during the time of flowering of the grasses. Kammann ${ }^{1}$ and Prausnitz ${ }^{2}$ were able to prove the incorrectness of this assertion and showed that pollen proteid does not penetrate into the circulation from the alimentary 1906 .

1 Kammaun, "Das Heufieber und, seine Serumbehandlung." Berl. klin. Wochenschr.

2 Prausnitz, "Heufiebergift u. Heufieberserum." Habilitationsschrift, Jena, 1912. 
canal, and cannot therefore produce antitoxin. Besides it has repeatedly been found that Graminol has no antitoxic property whatever. A certain number of hay-fever patients have stated that they were successful with Graminol. One author ${ }^{1}$ has pointed out that the manufacture of this substance is a trade secret and suggests that it might contain adrenaline. Others interested in the preparation endeavour to explain such results by denying the toxic character of the pollen proteid. These statements can now be considered as disproved and do not require any further discussion.

The specific pollen antitoxin is manufactured under the name of "Pollantin"." It is prepared firstly as (1) pollantinum liquidum : antitoxic horse serum $+\frac{1}{4} \%$ phenol. This preparation easily decomposes and the carbolic odour is unpleasant to many patients. For these reasons the (2) powdered pollantin has been prepared. Antitoxic serum is dried in a vacuum apparatus, powdered, and in this state keeps indefinitely without the addition of any antiseptic. The pure powder is liable to irritate the mucous membrane mechanically but this is prevented by the addition of lactose. Recently a new preparation has been manufactured, (3) pollantin R., specially designed for use in patients who are supersensitive, i.e. anaphylactic, to horse serum. At the desire of several physicians pollantin is also made up in the form of (4) an ointment. Lastly I have arranged for the preparation of (5) pollantin pastilles which have been used successfully by several patients against the asthmatic symptoms.

The mode of employment of these substances is very simple. The fluid as well as the powdered pollantin and the ointment is applied in minute quantities to the mucous membranes of the eyes, nose and mouth. It is important to do this before the onset of symptoms of irritation. This fundamental principle is neglected by many patients.

When the mucous membranes have become congested and oedematous, the antitoxin ceases to be absorbed by them. On the other hand it can only be administered locally, subcutaneous or intravenous application being impossible because the effect of the serum would not last for more than a day or two. The repeated injection of a foreign serum cannot be practised owing to the danger of serum-anaphylaxis. This point I shall refer to presently.

1 R. Hoffmann, "Beitrag zur Lehre u. Ther. d. Heufiebers." Mon. f. Ohrenheilk. $u$. Laryngol. 1910, vol. v. p. 883.

2 Manufactured by Messrs Schimmel \& Co, in Miltitz; Agents for the United States, Messrs Fritzsche Bros., New York, 
A second mistake commonly made by hay-fever patients is the use of far too large quantities of pollantin. From the very first I laid great stress upon the application of only minute amounts of the substance. The antitoxic effect of pollantin is so considerable, that a particle of the powder suffices to neutralise all the pollen toxin which can attack a patient in the course of a day. The employment of unnecessarily large doses renders many patients supersensitive (anaphylactic) to horse serum.

Such symptoms of horse serum anaphylaxis were observed by some patients as early as 1905. At that time our knowledge of this condition was comparatively slight. Even at that time $I^{1}$ was able to prove that the irritative effect of the serum had no connection with its antitoxic potency, for these patients showed the same reaction when normal horse serum was applied to their mucous membranes. It was noteworthy that hay-fever patients could render their whole body anaphylactic by simple treatment of the conjunctival membrane, the condition being shown by the uninjured skin reacting with itching, burning and erythema to the instillation of a drop of normal horse serum, which thus acts practically like the pollen proteid. Similarly in hay-fever patients who have become anaphylactic, horse serum affects the conjunctival and nasal membranes exactly like pollen toxin. That is the reason why several patients wrote to me that antitoxin caused or increased the hay-fever attack instead of curing it. In every case where normal serum was tested patients admitted that it also produced symptoms resembling hay-fever.

As a matter of fact horse serum anaphylaxis does not seem to occur very commonly among hay-fever patients - which individuals I used to regard as specially liable to this affection-the first impression I received from a large amount of direct correspondence was that it must be a fairly prevalent condition. But an enquiry instituted recently has shown that a very large percentage has used the remedy every year without being in the least irritated by it. Nor would thousands of hay-fever patients employ it every year if they had to suffer from anaphylactic symptoms; the majority of them are far too impatient for this supposition to be probable. For many years I have endeavoured to remove these irritating substances from the antitoxin-hitherto in vain. There was not indeed much hope of success, for as early as $\mathbf{1 9 0 5}$ I found this property was connected with the euglobulin of the serum

\footnotetext{
1 Dunbar, "Aetiologie u. spez. Ther. d. Heufiebers." Berl. klin. Woch. 1905,
} Nos. 26, 28-30. 
as is the antitoxin itself. If therefore you destroy the euglobulin-from which the anaphylaxia-producing bodies are inseparable-you also break down the antitoxin.

There are two ways by which I was able to help patients who had thus acquired anaphylaxis. One was the employment of the diluted preparation (pollantin R.) together with the advice to use this preparation only before the beginning of an attack, and to apply it in most minute quantities once a day or if possible at still longer intervals. Patients who tried this procedure informed me that the preparation did not irritate them at first but did do so later on. This agrees with my own experience. They found the irritation however to be tolerable and to disappear after 20 or 30 minutes, the result being that they afterwards remained free from attacks for the whole or even several days.

Another method was based upon the fact that horse serum anaphylaxis is specific in most, though not in all persons. Thus I have heard of cases where anaphylaxis having developed against one animal serum, patients also became supersensitive to others. But that is an exceptional condition. For this reason I supplied patients irritated by pollantin R. with a highly potent rabbit serum, the results being excellent. They were not only quite unaffected by the serum but also remained hay-fever free in the midst of the season. Unfortunately however in such patients supersensitiveness to rabbit serum also developed after a time.

Several years ago I suggested that in the same measure in which sensitiveness to sera is increased, the reaction to antitoxin would also grow, together with a tendency towards definite immunisation. Persons who have become anaphylactic in my experience require far smaller quantities of antitoxin than other patients, and have, I believe, better chances of definitely losing their susceptibility.

This of course must be the aim of specific treatment in hay-fever. Years ago I learnt of several patients, some of them very severe cases, who after comparatively short use of pollantin ceased to suffer from hay-fever attacks although they used no preventive measures or remedies. Such persons I believe to have been completely cured and I published this view last year ${ }^{1}$. In consequence of this publication a nasal specialist interested in hay-fever wrote that he could not understand such results for neither he nor any of his friends had ever observed such cases. In addition, my favourable results were in direct opposition to those of the German Hay-Fever Association. My endeavour to

1 Dunbar, "Zur Ursache u. spezifische Heilung d. Heufiebers." Deutsche med. Wochenschr. 1911, No. 13. 
defend myself against such attacks led me to place my material at the disposal of Dr Albrecht, the Secretary of the German Hay-Fever Association. I was agreeably surprised to learn that he himself had seen numerous cases in which pollantin had not merely cured the attacks but had produced real immunisation. In a recent publication ${ }^{1}$ he was able to report upon no less than 18 cases in which after a comparatively brief use of the remedy the hay-fever attacks ceased entirely or were at least markedly reduced. These observations appear to me to be of paramount interest in relation to hay-fever and I should be grateful if any colleague who has seen similar cases would communicate them to me.

The occurrence of horse serum anaphylaxis in hay-fever patients using pollantin has led me to pursue my investigations on this subject since 1905. All endeavours to prevent it have been in vain. On the other hand I found that it only occurred in a comparatively small percentage of cases, and that it then is regularly an indication of a decline in the hay-fever predisposition. Several such patients have repeatedly informed me that in spite of using only very small amounts of diluted pollantin they were able to keep themselves in a satisfactory condition throughout the season; they were able to pursue their avocations and often only required to employ the antitoxin at intervals of several days. Nevertheless this condition was not desirable, especially since the alternative use of antitoxin from the rabbit was also soon followed by anaphylaxis. Such experiences convinced me of the desirability of recommencing experiments on active immunisation. The chief consideration which caused me to hesitate was connecter with the grave symptoms that occurred at the beginning of my experiments, i.e. before the time of exact dosage. Subsequently I was doubtful for a time whether hay-fever was an anaphylactic condition, as has been most definitely asserted by several authors. Only recently have these doubts disappeared owing to the toxin neutralisation experiments described previously. I did not expect too much from active immunisation, since every hay-fever patient is regularly exposed to the action of pollen toxin for six or eight weeks every year; thus one would expect him to be actively immunised by natural means were this at all possible. A friend has carried out systematic experiments to reduce the conjunctival sensitiveness by systematically instilling into the conjunctival membrane increasing amounts of toxin: these experiments were unsuccessful.

1 Albrecht, "Immunisierung gegen Heufieber." Deutsche med Wochenschr. 1912. 
I was thus led to suppose that a result might possibly be achieved by employing neutralised mixtures of toxin and antitoxin. The result of passive immunisation, i.e. by employing antitoxin, seemed to favour this view. For the pollen toxin to which these patients were normally exposed year by year did not cure them; but definite immunity occurred as soon as the toxin was properly neutralised by the correct use of antitoxin throughout the hay-fever season. Before beginning to immunise patients with neutral mixtures of pollen toxin and antitoxin I hesitated for a time from fear of horse serum anaphylaxis. But experienced physicians, particularly specialists in children's diseases, reassured me by the information that they had for years given many of their patients subcutaneous injections of very large quantities of diphtheria antitoxic serum from the horse without witnessing anaphylactic symptoms. I therefore began these experiments by giving a neutralised mixture of grass pollen toxin and antitoxin subcutaneously to a patient who had for a considerable time used pollantin successfully without becoming supersensitive to horse serum. The injection was borne well. At the site of injection a slight sensation of warmth was felt, but no itching and burning and no other morbid symptoms followed. The only noticeable feature was a swelling about two inches in diameter round the injection which disappeared after 24 hours. Before treatment the patient showed a subjective and objective reaction with one drop of pollen toxin "Ka. VII" diluted 1:10,000,000. He received altogether 15 injections lasting well into the hay-fever period. The local reactions were less after the second injection and remained slight with the later ones, although the amount of toxin was doubled each time. The first injection was performed with a neutralised solution of toxin $1: 50,000,000$, the last with a solution of $1: 40,000$.

The immunising effect of such treatment was proved by the fact that in spite of this rapid increase in the dose no hay-fever symptoms followed the injection and the local reaction diminished. The limit of toxic action on the conjunctiva was reduced from $1: 10,000,000$ to $1: 100,000$.

The patient had been known to me for a long time; his relatives had frequently complained how intolerably he suffered during the hay-fever season. In this year no symptoms occurred at the time when other hay-fever patients were suffering and the number of grass pollen in the air was found by Dr Gaehtgens to have reached a considerable level. At my suggestion the patient took long walks and even went to Thuringia for a six days' trip in the early part of June, i.e. during the 
bad season for hay-fever patients, and was in the open all the time. Yet he remained practically free until the return journey. In the train he suffered from several rather severe attacks which rapidly ceased after the use of pollantin. The symptoms were practically limited to sneezing, he had felt remarkably free from any sensation of illness which formerly used to trouble him greatly. Immediately after his return to Hamburg he resumed his long walks in the open and only on seven days suffered from somewhat severe sneezing attacks which he was almost always able to relieve promptly by pollantin.

I propose to treat several other patients with neutralised toxin antitoxin mixtures in order to determine whether permanent immunity can be obtained by this treatment corresponding to that described in Dr Albrecht's cases. I am particularly interested in comparing such results with those obtained by purely active immunisation.

However successful this method may have been, it was not applicable in those patients who had developed anaphylaxis and who were therefore of particular importance. Those patients who are completely successful with the simple external application of pollen antitoxin and can keep free from attacks by this means alone have no reason to exchange it for a more complicated and more expensive method of treatment.

The active inmunisation of hay-fever patients appeared somewhat hopeless at the beginning of my experiments since hay-fever patients do not become immunised during their yearly period of illness. The view that the body would not react to the local attack of pollen which normally settles on the mucous membranes, but would respond with the production of anti-bodies to the direct injection of the poison into the subcutaneous tissues, appeared improbable, since I had proved that pollen toxin occasionally penetrates through the skin or mucous membrane and enters the body in the form of a genuine proteid. Since then I have found such penetration to occur but rarely. The results of local active immunisation of the conjunctiva mentioned previously were also unsuccessful. Yet Robert Koch, who took a considerable interest in my hay-fever investigations, repeatedly advised me to recommence experiments with active immunisation, beginning with minute doses.

Recently such experiments have been undertaken in Sir Almroth Wright's laboratory by L. Noon ${ }^{1}$ and J. Freeman ${ }^{2}$. Several hay-fever

\footnotetext{
${ }^{1}$ L. Noon, "Prophylactic inoculation against hay-fever." Lancet, 1911, vol. I. p. 1572 .

2 J. Freeman, Ibid. vol. Ir. p. 814.
} 
patients were injected subcutaneously with increasing quantities of pollen extract at intervals of three to 14 days. The susceptibility of the conjunctiva was found to decline during this treatment. If too large doses of the poison were given, the susceptibility showed a passing increase (negative phase of Wright). The authors were able to reduce the susceptibility to about $\frac{1}{100}$ of the original, i.e. to a limit which doubtless would suffice to render many patients resistant to the effect of the pollen quantities to which they are normally exposed.

The experiments of Noon were continued by Freeman on 20 patients. He also reduced the susceptibility of the conjunctiva to between $\frac{1}{10}$ and ${ }^{1} \frac{1}{\delta} \overline{0}$ of the origiual. Three patients seemed to have had a satisfactory result, 13 were markedly improved, whilst two cases were not influenced. The reduction of conjunctival susceptibility bore a certain analogy to the clinical effect.

This result has been regarded by others as an anti-anaphylactic condition. I also was at first inclined to fear that an artificial immunity obtained by a purely active method would have no lasting effect. Freeman has since informed me that his results were satisfactory in 1912. In persons, who had been actively immunised in the previous year, the degree of immunity which had fallen considerably during the winter was raised to a very high level without any unpleasant symptoms by means of a single injection.

My experiments were recommenced in April 1912, such patients being chiefly selected who had become highly anaphylactic to horse serum. I also treated the severest cases that I knew, patients who complained that they had to give up their profession owing to hayfever, that throughout the season they found no peace at night from asthmatic symptoms and in the day time were unable to leave the room.

I have altogether treated ten patients, one of these being the case already mentioned where toxin antitoxin mixtures were administered. At the same time a person not affected by hay-fever was also injected subcutaneously with increasing doses of pollen toxin. This individual, as was to be expected, did not acquire hay-fever, and the injections were followed by no symptoms whatever either before or during the hay-fever period.

The treatment of most of the patients was begun between the 29th April and 8th May, i.e. several weeks before the beginning of the hay-fever period. This was ascertained for Hamburg to be the 30th May. In two patients treatment did not begin till the 7 th and 
11th June respectively, i.e. at the worst time of our hay-fever period when the rye was in full flower.

The first dose in all patients was chosen according to their susceptibility as determined by the ophthalmo reaction; if e.g. the conjunctiva reacted to one drop of a toxin solution $1: 100,000,000$, the patient was injected with 1 c.c. of a solution $1: 300,000,000$, and so on. All patients reacted to the first injection with a swelling at the site of injection, which was one to six inches in length, hard, red, hot, and itching. The toxin doses were doubled every time, yet at the second injection performed five or six days later, the local reaction was already less marked in several of the patients, and at the subsequent injections it was either quite absent or at any rate slight.

Only in my own case and in that of another very highly susceptible patient who used to suffer from severe asthma, a rapid increase in the dose of toxin was followed by general symptoms in addition to the local reaction. These general symptoms correspond with those described in an earlier publication ${ }^{1}$, so that I need not enter into details in regard to them. They however always remained within moderate limits and were less distressing than a typical hay-fever attack, excepting perhaps an oedematous swelling of the eyelids which lasted for two days.

In my case the toxin dose was increased to 1500 times the original, the reactions being considerably less than after the first dose. In the other patients the concluding dose was increased to between 50 and 2000 times the original dose. These high multiples either produced no reaction or at least less intense symptoms than the initial dose.

During the hay-fever season the following observations were made on the seven patients who had begun treatment before the time of their illness.

I have myself for a number of years possessed a certain degree of immunity; thus I only suffered from slight transitory attacks of sneezing when I was much in the open or travelled by train on days when the pollen count in the air was high. In this year I was able to remain out of doors even on such days without experiencing any attacks. A journey of three weeks duration, in the course of which I was almost daily moving about among flowering meadows, conclusively showed that through the systematic toxin injections my susceptibility had been still further diminished.

Of the remaining patients only one had shown an indication of immunity in the year before. All the other cases were severe and

1 Dunbar, Zur Ursache u. spez. Heilg. d. Hcuf. München, 1903, pp. 32-35. 
complicated either by horse serum anaphylaxis or by pollen asthma. They all declared that formerly they had suffered daily for six or eight weeks, even if they did not leave the house and in spite of an exhaustive application of all manner of pharmaceutical remedies. Even in this small number of cases I have seen how difficult it is to obtain exact numerical replies as to the effect of treatment in hay-fever.

Thus one patient stated early in June that he could remember no year in which he had been so free from attacks as this one, in spite of undertaking things he would not have done previously, e.g. railway journeys etc. At the end of treatment, however, he asserted that the whole treatment had not benefited him in the least. Yet when reminded of his original statement, he admitted that the attacks had been less frequent and less severe than in previous years.

A second case was quite similar. Although the patient did not say that the treatment had not benefited him at all, he still did not think very much of it.

In a third patient the treatment was interrupted on the 10th June because he had to leave town. Up to then he had been out of doors a great deal during the worst part of the hay-fever season as a yachtsman, but had suffered only from very mild sneezing attacks. He was himself convinced that he had had far better results than ever before.

Another patient used to suffer-in spite of all precautions-from a most intense feeling of illness in addition to the ordinary symptoms of sneezing, watering of the eyes, etc. Although he took fewer precantions this year and was very much out of doors, he suffered only on six days with mild sneezing attacks and only on one day experienced a characteristic feeling of illness. Another case was quite similar. A third patient had formerly been forced to remain in doors throughout the season, was unable to follow his profession, and yet suffered severely from asthma. In this season he was able to follow his profession all the time. What is more, he travelled about by motor and by train, yet only had mild or moderate sneezing attacks on five days, i.e. three or four sneezes without any sensation of illness. Such sensation of illness was experienced only on one day in this year. It was associated with moderate asthma and followed a two hours motor drive on the 29th June. Now on this day our pollen counts in the centre of the city had given the amount of 273,000 pollen per square metre. In all these patients the susceptibility had fallen to between $\frac{1}{20}$ and $\frac{1}{100}$ of the original.

Of the two cases where treatment was begun in the middle of the 
hay-fever season, one experienced no benefit. The other patient remained entirely free from attacks after the 30th June, i.e. about three weeks after the beginning of the treatment, although he lives in a house surrounded by meadows and is forced by his profession to be out of doors a great deal.

The foregoing remarks show that experiments with active immunisation in hay-fever appear hopeful. Statistics will doubtless be far more satisfactory, as soon as the experiments are extended to ordinary cases, not being confined to the most severe ones. Further it should not be lost sight of that in the latter we were unable to commence treatment until four weeks before the beginning of the disease. A further considerable improvement in our results may be expected, if inoculation is begun several months before the hay-fever season, as was done by Noon and Freeman.

Both from practical and scientific considerations it was important to prove that the injections can be performed without any annoyance worth mentioning being caused to the patient. Still I would strongly advise that they should never be undertaken before the limits of the patient's susceptibility by the ophthalmo-reaction has been ascertained.

The results obtained appear so satisfactory to me that I propose extending my investigations on a considerably larger scale in the future. 